\title{
A Pedestrian Approach to Indoor Temperature Distribution Prediction of a Passive Solar Energy Efficient House
}

\author{
Golden Makaka \\ University of Fort Hare, Private Bag Box X1314, Alice 5700, South Africa \\ Correspondence should be addressed to Golden Makaka; gmakaka@ufh.ac.za
}

Received 23 April 2015; Accepted 15 October 2015

Academic Editor: Cheng-Xian Lin

Copyright ( 2015 Golden Makaka. This is an open access article distributed under the Creative Commons Attribution License, which permits unrestricted use, distribution, and reproduction in any medium, provided the original work is properly cited.

\begin{abstract}
With the increase in energy consumption by buildings in keeping the indoor environment within the comfort levels and the ever increase of energy price there is need to design buildings that require minimal energy to keep the indoor environment within the comfort levels. There is need to predict the indoor temperature during the design stage. In this paper a statistical indoor temperature prediction model was developed. A passive solar house was constructed; thermal behaviour was simulated using ECOTECT and DOE computer software. The thermal behaviour of the house was monitored for a year. The indoor temperature was observed to be in the comfort level for $85 \%$ of the total time monitored. The simulation results were compared with the measured results and those from the prediction model. The statistical prediction model was found to agree (95\%) with the measured results. Simulation results were observed to agree (96\%) with the statistical prediction model. Modeled indoor temperature was most sensitive to the outdoor temperatures variations. The daily mean peak ones were found to be more pronounced in summer (5\%) than in winter (4\%). The developed model can be used to predict the instantaneous indoor temperature for a specific house design.
\end{abstract}

\section{Introduction}

In the recent years indoor temperature distributions are gaining greater attention in building design and operations [1]. Due to high energy consumption by buildings and the ever energy price increase there is an urgent need to predict the indoor temperature distribution and energy consumption by building during the design stage [2]. Detailed and precise predictions of indoor thermal comfort and control of the indoor thermal conditions and fast dynamic model of the indoor temperature distribution are needed in the design stage of buildings so as to select the correct materials that will produce a thermally comfortable indoor environment [3]. This can result in the reduction of energy consumption in trying to keep the indoor environment within the temperature comfort levels $\left(18^{\circ} \mathrm{C}\right.$ to $\left.28^{\circ} \mathrm{C}\right)$ and relative humidity (30\% to $70 \%$ ) [4]. Due to the diversity of building materials and climates there is need to pay particular attention to material properties and the availability of suitable materials in different local areas to minimize construction costs. Recently an amount of building computer design software has been developed to simulate indoor temperature distributions including ECOTECT, DOE, ESP-r, and EnergyPlus [5].

ECOTECT is a complete building design and environmental analysis tool that covers the full range of simulation and analysis functions required to understand how a building design will operate and perform. It allows designers to work easily in 3D and apply all the tools necessary for an energy efficient and sustainable future.

The DOE provides the building construction and research communities with an up-to-date, unbiased, well-documented computer program for building energy analysis. Using DOE, designers can quickly determine the choice of building parameters which improve energy efficiency while maintaining thermal comfort. A user can provide a simple or increasingly detailed description of a building design or alternative design options and obtain an accurate estimate of the proposed building's energy consumption, interior environmental conditions, and energy operation cost.

The present predicting indoor temperature methods are cumbersome. However, fast and simpler predicting indoor temperature models need to be developed to help architects to 
design buildings with thermally comfortable indoor environment and thus advise building constructors to select better thermally performing building materials.

The mathematical description of thermal behaviour of building systems is complex [6] as most of the parameters involved are probabilistic in behaviour. The activities associated with each room (subsystem, e.g., kitchen and bathroom) complicate indoor temperature modeling process. The positioning of heat sources and their frequency of use do have a significant impact on the indoor temperature distribution. The modeling of the thermal behaviour involves the modeling of several interconnected subsystems, with each one containing long-time constants, nonlinearities, and uncertainties such as convection coefficients and material properties [7]. Moreover, external unpredicted perturbations such as temperature and relative humidity, soil temperature, solar radiation effects, and other sources of energy such as people illumination and equipment should be taken into account [8]. The generalized mathematical model for predicting indoor temperature of any building has to take into account the weather conditions to which the building is exposed and thermal properties of the building [9].

A number of indoor temperature predicting models have been developed. Givoni [10] developed very simple experimental predictive formula of the indoor temperatures of uninhabited houses. It was demonstrated that the indoor daily maximum and daily average temperatures (in degree Celsius) could be predicted on the basis of only the daily outdoors average temperatures. The formula developed by Givoni was as follows:

$$
T_{\text {max-in }}=T_{\text {max-out }}-0.3\left(T_{\text {max-out }}-T_{\text {min-out }}\right)+1.6,
$$

where $T_{\max \text {-in }}$ is the indoor maximum temperature, $T_{\max \text {-out }}$ is the outdoor maximum temperature, and $T_{\text {min-out }}$ is the outdoor minimum temperature.

Ogoli [11] also did a similar study and developed the following formula:

$$
T_{\max -i n}=T_{\max -\text { out }}-0.4\left(T_{\max -\text { out }}-T_{\text {min-out }}\right)+2.44
$$

Construction materials also have a significant impact on the indoor temperature distribution. The properties of construction materials were also attributed to different leveling temperature constants in (1) and (2) which are $1.6^{\circ} \mathrm{C}$ and $2.44^{\circ} \mathrm{C}$, respectively. The differences between the formulae of Givoni [12] and Ogoli [11] were also due to the different weather conditions and the fact that Givoni's study was carried out in open naturally ventilated test chambers, while Ogoli's study was for closed test chambers. Givoni and Ogoli only considered the outdoor temperature as the only influencing parameter to the indoor temperature. However, the indoor temperature is affected by a number of parameters, which include wind speed and direction, relative humidity, solar radiation, outdoor temperature, and landscape [13]. Some of these parameters are not independent, for example, relative humidity and temperature [14]. High wind speeds have the tendency to lower the indoor temperature and the effect depends on the wind direction with respect to window orientations and their operation. High solar radiation heats the walls and roof which in turn transfer the thermal energy through conduction and convection to the indoor environment. In an unoccupied house one can have a complete control over the conditions of the house, whether to open or close, shade or unshade the windows, and so forth. In occupied buildings the situation is very different as the occupants have complete freedom to change the conditions according to their changing needs. The activities of the occupants have a significant influence on the indoor temperature distribution [15].

Hemmi [16] developed a model which divides the room air volume into several ideally mixed zones that were connected both in series and in parallel with respect to the mass air flow in the room. The precondition for the model of Hemmi was that the air mass flow between one zone and another could be prescribed but Hemmi never gave a theoretical method of how it could be prescribed. Peng and van Paassen [17] studied the prediction of indoor dynamic temperature distributions by using a fixed-flow-field obtained from (computational fluid dynamics) CFD calculation. The fundamental differential equations in CFD are the continuity, momentum conservation, and energy conservation equations. The basic idea of CFD is that the flow domain is first divided in thousands of finite volumes by setting a grid. For every finite volume of the grid, the conservation equations are solved iteratively until the solutions of all variables for all volumes have converged. However, CFD method is timeconsuming [18] and faster easy methods are needed to predict indoor temperature distribution and assist architects to design buildings according to thermal performance.

Another very important approach is the statistical model approach. This approach allows estimating the probabilistic future thermal behaviour of buildings based on monitored statistical information, such as outdoor temperature and relative humidity. The thermal performance of buildings is probabilistic as it does depend on a number of stochastic parameters such as the occupants' behaviour in operating the ventilation components and indoor human activities. Some can even choose to close doors to avoid pets getting inside thus compromising the thermal performance of the house. Indoor temperature depends not only on outdoor temperature but also on other parameters such as occupants and heat producing equipment (whether they are on or off). These parameters sometimes are uncertain and in some cases are difficult to find the exact information. This leads to the uncertainty in indoor temperature calculation result. Parameters which affect indoor temperature can be divided into two types, that is, uncontrollable and controllable parameters. Uncontrollable parameters such as ambient air temperature, wind direction and speed, and solar radiation affect the change in the probability of the indoor temperature distribution, while controllable parameters, such as type and shading coefficient of glass, do not affect the change in the probability of the indoor temperature variation.

The aim of this paper is to use the statistical method to predict the indoor temperature distribution in occupied low cost passive solar house constructed from fly ash bricks. Fly ash bricks were used because of their advantageous 
properties, low thermal conductivity, low water absorption, and high thermal compression [4]. The model house, passive solar house (PSH), was built in Somerset East (South Africa) which has the following properties: $32^{\circ} 42 / S$ latitude, $25^{\circ} 33 / \mathrm{E}$ longitude, and an altitude of $790 \mathrm{~m}$. It experiences a subtropical type of climate with long hot summer months and moderate sunny winter months with annual daily average of 7-8 sunshine hours [19].

During the monitoring period three people were staying in the house, a couple and their grandson. The two were pensioners and they were always at home, while the grandson attends school from 07:30 to 13:00.

\section{Methodology}

2.1. Simulation. The modeling approach in this study includes the following:

(i) Selection of indoor temperature simulation software (ECOTECT and DOE were selected).

(ii) Development of the passive solar house (PSH) model that could be deployed for the indoor temperature simulation.

(iii) Construction of the PSH model.

(iv) Monitoring the thermal behaviour of the PSH model.

(v) Development of the statistical model for the prediction of the indoor temperature.

The simulation results from DOE and ECOTECT were compared with the developed statistical predicting model. ECOTECT was used in the simulation process because it has the ability to identify the input files of a building by drawing a model of the building and it has the ability to export the input data to other simulation modeling programs, such as DOE. For the purpose of simulation the following parameters were entered: temperature, relative humidity, diffuse solar radiation, global radiation, wind speed, cloud cover, rainfall, wall thickness, types of wall materials, types of roof materials, type of glass window, window closed or open, type of floor material, length of overhangs, and slab thickness.

2.2. Data Acquisition System. Monitoring sensors were installed indoors and outdoors. A weather station was installed to measure the comfort parameters, that is, wind speed and direction, solar radiation, temperature, and humidity. Figure 1 shows the weather station installed on the top of the roof and the automated data acquisition system. Sensors installed to monitor the thermal performance of the house included 26 Type $\mathrm{K}$ thermocouples for the measurement of outdoor and indoor air temperatures, 2 HMP50 temperature-humidity probe, model 03001 wind sentry anemometer and vane, and a pyranometer.

Thermocouples were placed at three height levels, thus creating three planes: the lower plane level at a height of $z=1 \mathrm{~m}$, the middle plane level at a height of $z=$ $1.5 \mathrm{~m}$, and the upper plane level at a height of $z=2.6 \mathrm{~m}$. The thermocouples for lower plane level are labeled: 26 , $19,20,21,22,23,18$, and 25; for the middle plane level they are labeled: $17,10,11,12,13,14,6$, and 16; and for the upper plane level they are labeled: $8,1,2,3,4,9,5,15,24$, and 7. Figure 2 shows how thermocouples were distributed to measure indoor and outdoor temperatures. A HMP50 temperature-humidity sensor was placed in the centre of the building at a height of about $2 \mathrm{~m}$ above the floor, while the second HMP50 temperature-humidity sensor was placed on the top of the roof. All sensors were connected to a CR1000 data logger and readings were recorded at 30-minute interval.

2.3. Design of the Model House (PSH). The house design was made to minimize space-conditioning loads by using fly ash brick walls and a concrete floor as the thermal mass. The house floor plan measured $6880 \mathrm{~mm}$ by $6580 \mathrm{~mm}$. An open plan layout was adopted in order to optimize natural ventilation since mechanical ventilation systems were avoided to keep the running cost of the house low. The roof was split into two, the lower and upper roof. The lower roof faces north, while the higher roof faces south. This was done to insert clerestory windows making it possible to direct solar radiation to the desired rear zone (floor and southern wall) and to maximize day lighting, thus minimizing the use of electricity during the day. A door and two windows are on the north wall, a door and a small window are on the west wall, two windows are on the south wall, and one small window is on the east wall. Table 1 shows the performance parameters of materials used to construct the PSH. Thermal admittance is a measure of a material's ability to absorb heat from and release heat to a space over time and this gives an indication of the thermal storage capacity of a material. Thermal admittance $(Y)$ is calculated as $Y=(Q / A) \Delta T$, where $Q$ is the heat transfer, $A$ is the surface area, and $\Delta T$ is the temperature differences between the surfaces of the material. The thicker and more resistive the material is the longer it will take for heat waves to pass through. The time delay due to the thermal mass is known as a time lag. The reduction in temperature on the inside surface compared to the outside surface is known as decrement factor. The decrement factor is calculated as $\Gamma=\left(T_{\text {out }}-T_{\text {in }}\right) / T_{\text {out }}$, where $T_{\text {out }}>T_{\text {in }}$.

2.4. Operation of the House. In winter (May to August) the sun rises almost at the northeast but following a low northern path in the sky and then sets at the northwest. From May to August the maximum sun's angle of each day ranges from $34^{\circ}$ to $45^{\circ}$ and these maximum angles occur at around 12:15 pm local time with 21st June having the smallest angle. So the north facing windows allow solar radiation to enter the house and the clerestory windows allow the south wall and the far south floor to receive solar radiation. The thermal masses of high heat capacity (i.e., concrete floor of $100 \mathrm{~mm}$ in thickness and the wall made from fly ash bricks) absorb the short wave solar radiation during the day. Figure 3 shows how the lower winter sun enters indoors and heats the thermal mass and how the summer sun is prevented from entering indoors by the overhangs.

Since the thermal masses have high heat capacity, they will absorb large amount of solar energy but with minimal temperature variation. This minimal temperature variation 


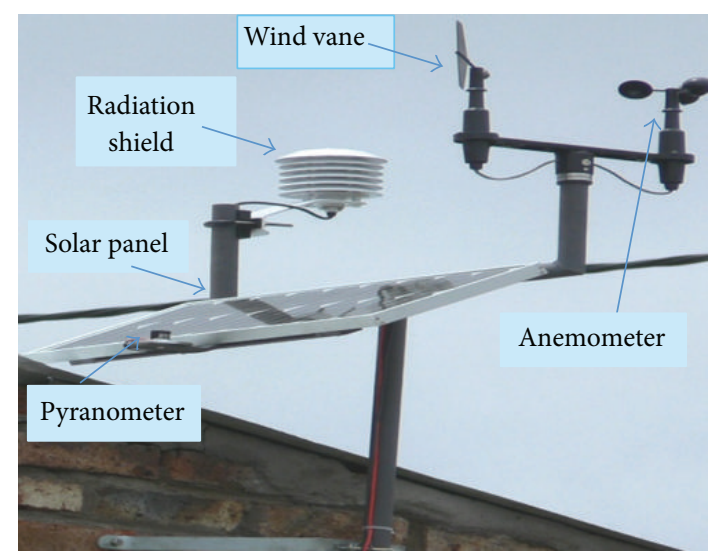

(a)

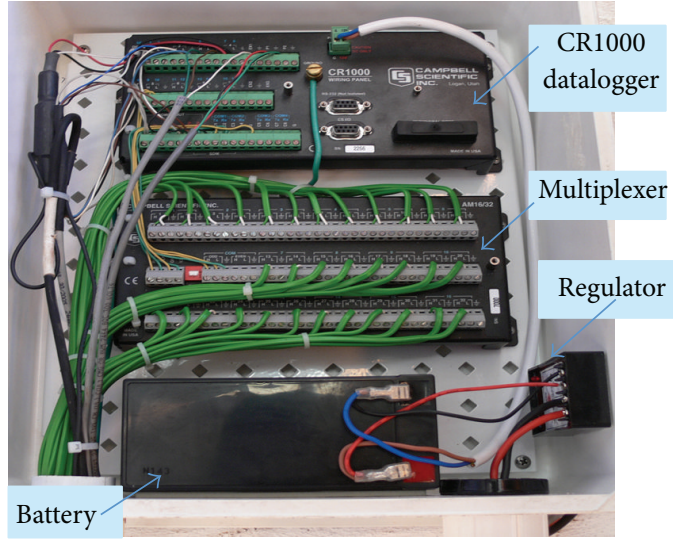

(b)

FIGURE 1: Experimental setup. (a) External sensors. (b) Automated data acquisition system.

TABLE 1: Properties of the basic material elements used in the construction of the PSH.

\begin{tabular}{lcccc}
\hline Element & $U$ value $\left(\mathrm{W} / \mathrm{m}^{2} \mathrm{~K}\right)$ & Admittance $\left(\mathrm{W} / \mathrm{m}^{2} \mathrm{~K}\right)$ & Thermal decrement & Thermal lag (hours) \\
\hline Floor & 2.56 & 4.20 & 0.70 & 4 \\
Roof & 7.14 & 7.10 & 0.00 & 1 \\
Wall & 1.78 & 4.59 & 0.37 & 8 \\
Window & 6.00 & 6.00 & - & - \\
\hline
\end{tabular}

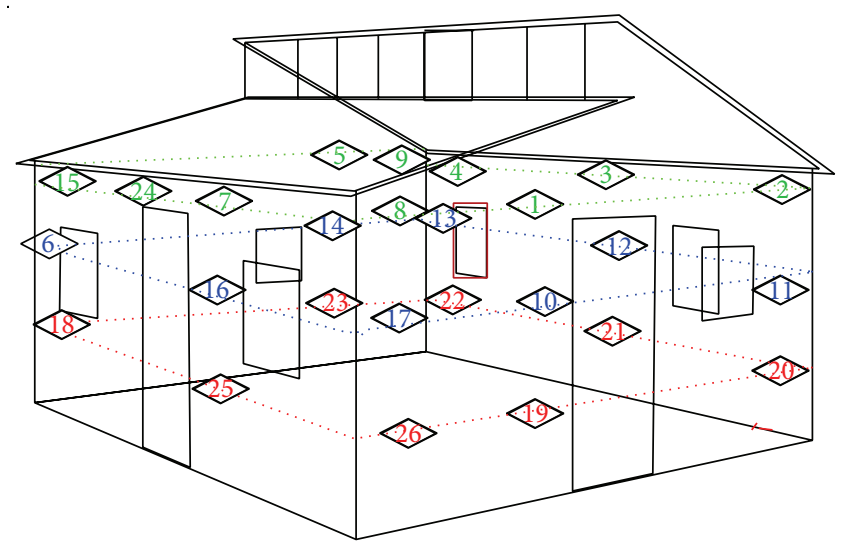

Red: lower level Blue: middle level

FIGURE 2: Distribution of thermocouples.

avoids the indoor overheat, thus keeping the indoor temperature within the comfort levels. At night, as the outdoor temperature falls, the thermal mass slowly radiates longwave radiation heating the indoor air therefore keeping the indoor air temperature within the thermal comfort levels. The window glazes are opaque to the long-wave thermal radiation, so the thermal radiation emitted by the thermal mass is trapped indoors and this minimizes the heat losses.

In summer the sun almost rises from the east and sets on the west and the overhangs on the windows eliminate the possibility of the sunrays to penetrate indoors. With reference to the clerestory windows, the upper roof was extended out by $200 \mathrm{~mm}$, while the lower roof was extended in by $100 \mathrm{~mm}$ and this arrangement eliminates the possible entrance of solar radiation in summer while allowing maximum entrance in winter. Somerset East experiences westerly prevailing winds in summer, so the small windows on the west and east make it possible to control the ventilation rate. The clerestory windows and the south windows enhance controllable natural ventilation rate and help to control the temperature to remain within the comfort zone $\left(18^{\circ} \mathrm{C}\right.$ to $\left.28^{\circ} \mathrm{C}\right)$.

\section{Results}

3.1. Outdoor and Indoor Temperatures. The behaviour of occupants was found to have a significant impact on the indoor thermal environment, that is, the management of the ventilation components (closing and opening of windows and doors). The indoor temperature within the building was found to be the result of heating and heat transfer between the building and the environment. Figure 4 shows the fluctuations of the indoor temperature in response to the outdoor temperature fluctuations.

A common feature observed was the tendency of similarity between the peak indoor temperatures and the peak outdoor temperatures. Givoni also saw this observation in several studies in California [10,12] and Israel [20]. The maximum indoor temperature was found to lag behind the maximum outdoor temperature by an average of two hours. From Figure 4 it can be observed that there is distinct general variation of the indoor temperature in response to the outdoor temperature for summer and winter. With reference 


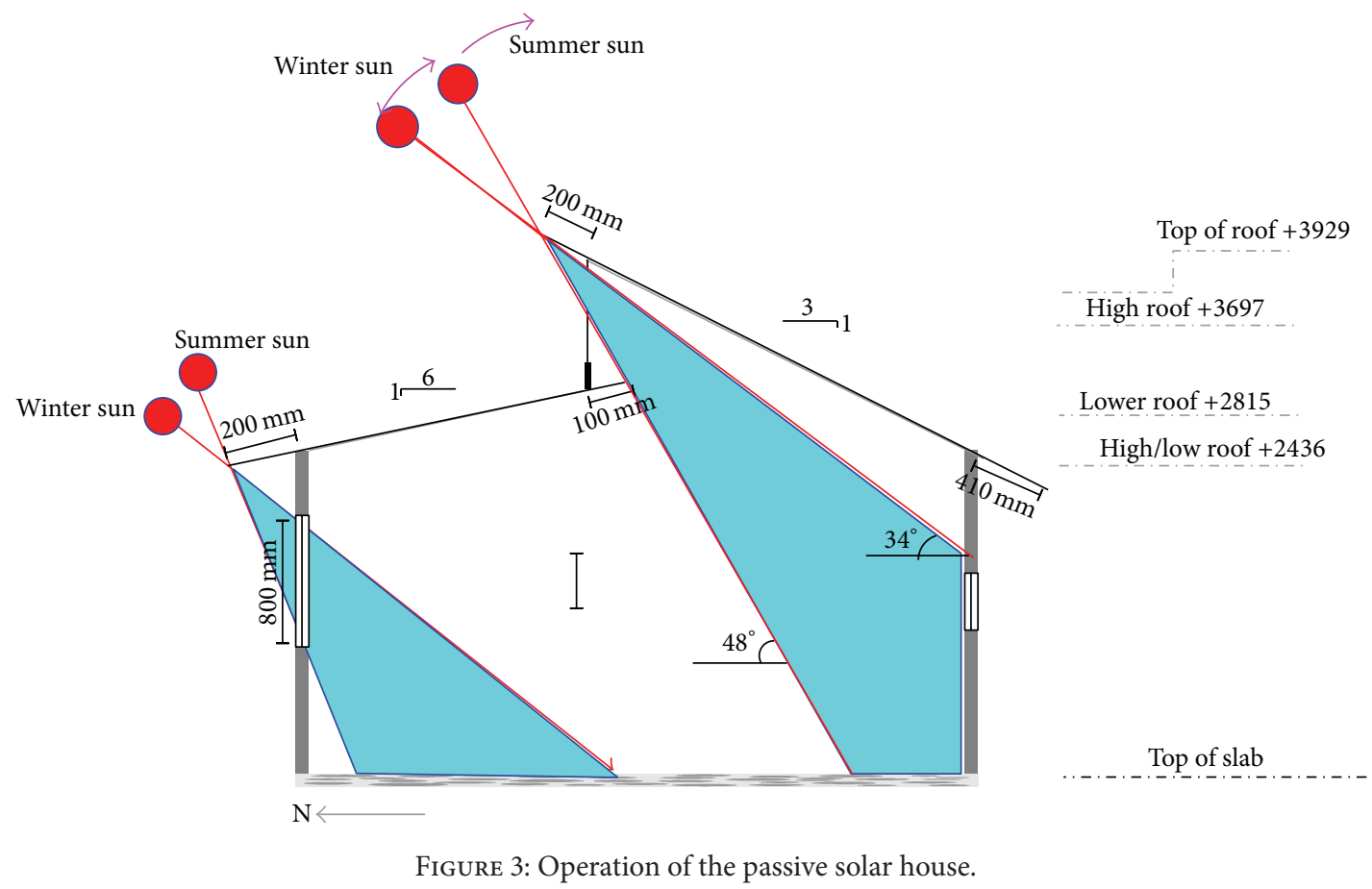

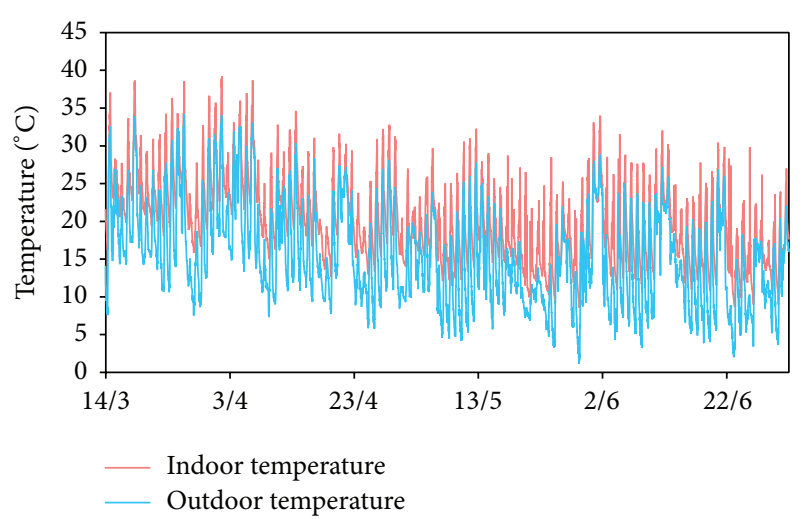

FIGURE 4: The response of the indoor and outdoor temperature variations.

to Figure 4, the average temperature and the daily mean temperature amplitude for the whole period were calculated. Using these parameters the best-fit equations for the daily temperature variations were established. Equations (3) and (4) are the best-fit equations for the daily general variation of the indoor and outdoor temperatures for the summer period:

$$
T_{\text {in }}=21.3+5.2 \cos \left(\frac{\pi}{12} t-\frac{7 \pi}{6}\right),
$$

with $R^{2}=0.974$ and standard error of $\pm 2 \%$;

$$
T_{\text {out }}=23.4+7.7 \cos \left(\frac{\pi}{12} t-\frac{4 \pi}{3}\right),
$$

with $R^{2}=0.988$ and standard error of $\pm 1.8 \%$.
Equations (5) and (6) are the best-fit equations for the variation of the indoor and outdoor temperatures for the winter period:

$$
T_{\text {in }}=19.5+4.5 \cos \left(\frac{\pi}{12} t-\frac{17}{12}\right),
$$

with $R^{2}=0.967$ and standard error of $\pm 2.2 \%$;

$$
T_{\text {out }}=16.7+9.2 \cos \left(\frac{\pi}{12} t-\frac{5 \pi}{4}\right)
$$

with $R^{2}=0.979$ and standard error of $\mp 2.1 \%$, where $T_{\text {out }}$ and $T_{\text {in }}$ are outdoor and indoor temperature, respectively. For the summer period the maximum outdoor temperatures were observed to occur at around 14:00 and the maximum indoor temperature occurred at around 16:00, while for the winter period the maximum outdoor temperature occurred at around 15:00 and the maximum indoor temperature occurred at around 17:00. With reference to (3) to (6) it was observed that in summer the average indoor temperature swing was about $10.4^{\circ} \mathrm{C}$, while in winter the average indoor temperature swing was about $9^{\circ} \mathrm{C}$.

The time delay ( 2 hours) of the indoor temperature to attain the peak value in relation to the outdoor temperature indicates that the wall materials used have high heat retention capacity with minimal temperature variation. This makes the indoor environment warm in winter, and in summer the sun shaded off thus keeping the indoor temperature within the comfort levels. When the sun sets at around 17:00 in winter the indoor air will be at highest temperatures thus keeping the indoor environment within the comfort levels for a considerable time eliminating the need of using heating devices. 


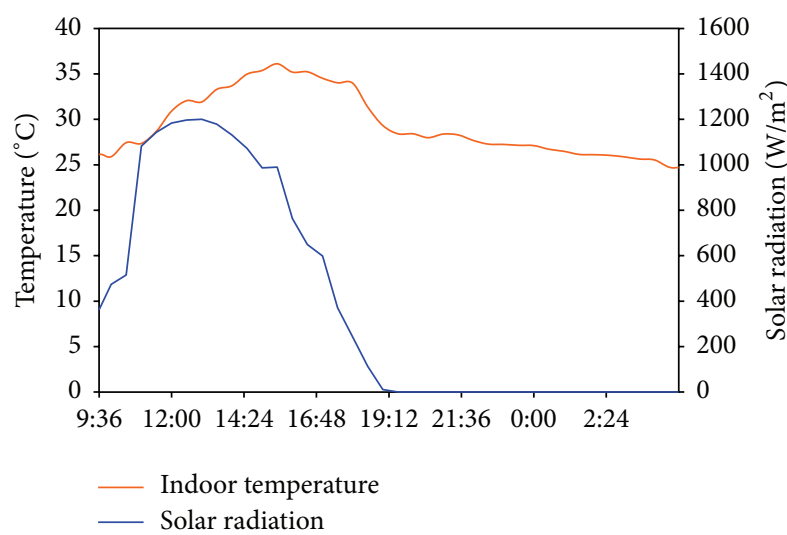

FIGURE 5: Variation of indoor temperature with solar radiation (5 November).

In South Africa the recommended indoor temperature comfort levels range from $18^{\circ} \mathrm{C}$ to $28^{\circ} \mathrm{C}$ and with reference to Figure 4 the indoor temperature was observed to be within the comfort levels for $85 \%$ of the time. This means that during this period there will be no need of heating/cooling the indoor environment resulting in energy saving. The indoor temperatures were always lower than the outdoor temperatures during the daytime but the situation was reversed during night time. As the sun sets the outdoor temperature falls much faster than the indoor temperature and heat flows from the inner walls to the outer walls. With reference to Figure 4 the mean indoor temperature was lower than the mean outdoor temperature by about $3.1^{\circ} \mathrm{C}$, while the mean indoor minimum temperatures were greater than the mean minimum outdoor temperature by $4.5^{\circ} \mathrm{C}$.

3.2. Variation of the Indoor Temperature with Solar Radiation. The solar radiation was seen to have a significant impact on the indoor temperature distribution. Figure 5 shows the variation of the indoor temperature with the solar radiation for a particular day ( 5 November). From Figure 5 it can be observed that the indoor temperature generally follows the fluctuations of the solar radiation but with a thermal time delay of about $2 \mathrm{~h} 30 \mathrm{~min}$.

The thermal time delay is due to the thermal inertia of the building materials used. The thermal time delay makes it possible for the indoor temperature to remain within the comfort levels during the winter nights.

Figures 6 and 7 show the daily maxima and minima temperature variations for winter and summer seasons, respectively. From the two graphs it can be seen that the summer period experienced higher daily indoor temperatures swings. In winter the mean maximum indoor temperature was found to be within the temperature comfort levels, while in summer it was above the upper bound comfort level by $5^{\circ} \mathrm{C}$. However, in winter, the mean minimum indoor temperature was lower than the lower bound comfort levels by $3^{\circ} \mathrm{C}$, while in summer the mean indoor temperature was within the comfort levels. During winter and night, the zinc roof loses thermal energy fast as the ambient temperature falls rapidly. However, this

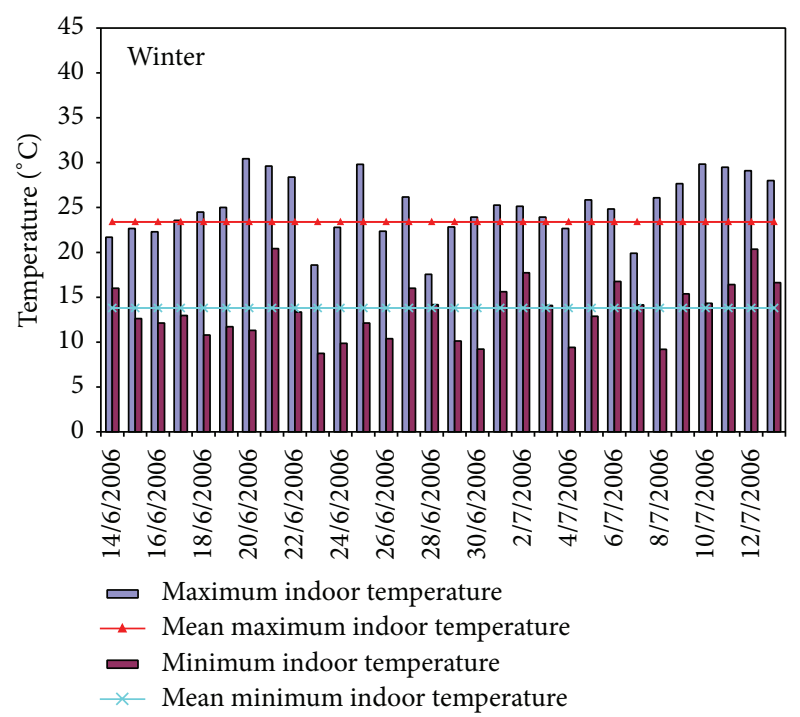

FIGURE 6: Daily maximum and minimum temperatures indoors during the winter period.

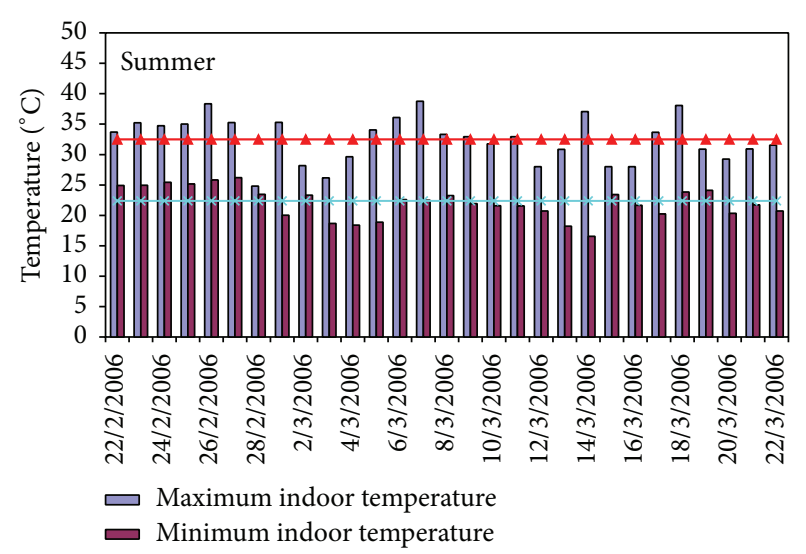

FIGURE 7: Daily maximum and minimum temperatures indoors during the summer period.

fast fall of temperature can be mitigated by the installation of ceiling thus maintaining the indoor temperature within the comfort levels.

3.3. Correlating Indoor and Outdoor Temperatures. Figure 8 shows the best-fit correlation of the indoor to the outdoor temperature. The correlation function was found to be as follows:

$$
\begin{aligned}
& T_{\text {in }}=1.0699 T_{\text {out }}-6.1731: \text { for } p=0.01 ; \\
& R^{2}=0.8594: \text { standard error of } \pm 2.312^{\circ} \mathrm{C} .
\end{aligned}
$$

From Figure 8 it was observed that the outdoor temperature has a significant impact on the indoor temperature. The data dispersion indicates that there are other outdoor weather parameters which affect the indoor temperature distribution. It must be noted that human activities significantly affect the indoor temperatures and this gives data dispersion. In the 


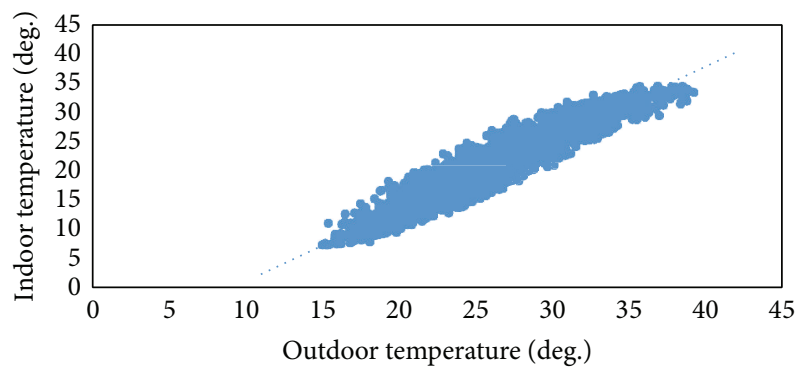

FIGURE 8: Variation of indoor and outdoor temperatures.

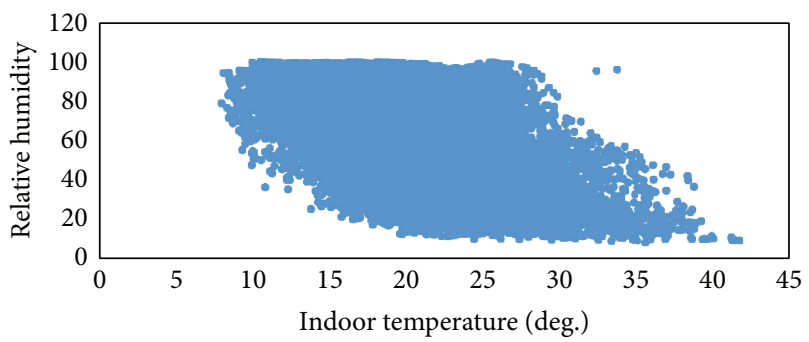

FIGURE 9: Variation of the indoor temperature with outdoor relative humidity.

morning the indoor temperature is generally higher than the outdoor temperature; however, as the sun rises, the outdoor temperature increases faster than the indoor temperature. The time lag of the indoor temperature in response to the outdoor temperature is contributed mainly by the thermal mass (walls), thus resulting in outdoor temperatures higher than the indoor temperatures.

3.4. Correlating $T_{\text {in }}$ and Outdoor Relative Humidity. Figure 9 shows the correlation of indoor temperature to outdoor relative humidity and high data dispersion was observed. The wide data dispersion means that the outdoor temperature is not the only outdoor weather parameter which affects the indoor temperature. The correlation function was found to be as follows:

$$
\begin{aligned}
T_{\text {in }} & =0.1184(\mathrm{RH})_{\text {out }}+33.389: \\
R^{2} & =0.3099 ; \text { standard error of } \pm 7.6^{\circ} \mathrm{C} .
\end{aligned}
$$

\subsection{Indoor Temperature Modeling for the Passive Solar House.} The performance of the house was observed to depend on how the occupants operate the house and it was assumed that there was no heating or cooling appliance used to modify the indoor thermal environment. Based on the monitoring results the first stage in the development of the experimental predictive model was to analyze the patterns of how the indoor temperature varies with outdoor weather parameters. Taking into account this possible dependence, a predictive model for the indoor temperature was developed. A linear dependence was proposed. Consider

$$
T_{\text {in }}\left(T_{\text {out }}, I, V_{\text {ws }}, \mathrm{RH}\right)=0 .
$$

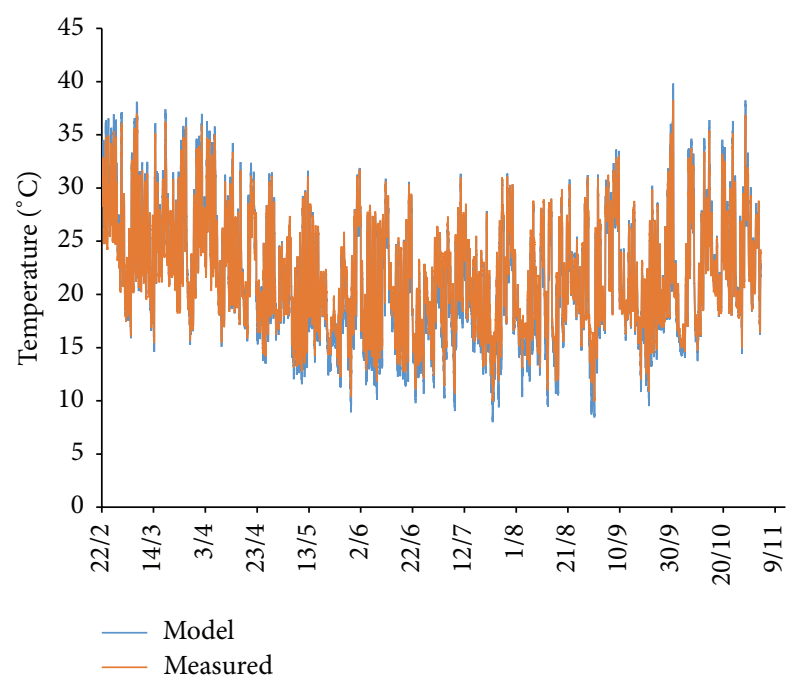

FIGURE 10: Comparison of the measured and the modeled temperatures.

The above formula can be expressed in the following form:

$$
\begin{aligned}
T_{\text {in }}= & a_{1} * T_{\text {out }}+a_{2} *(\mathrm{RH})_{\text {out }}+a_{3} * I+a_{4} * V_{w} \\
& +a_{5},
\end{aligned}
$$

where $T_{\text {in }}$ is indoor temperature, $T_{\text {out }}$ is outdoor temperature, $V_{w}$ is wind speed, $I$ is solar radiation, $\mathrm{RH}_{\text {out }}$ is outdoor relative humidity, and $a_{i}$ are regression coefficients, where $i=1,2,3,4,5$.

The above proposed model is a simplification of a complex dependence. It must be noted that all the parameters involved are not independent. For example, the outdoor temperature greatly depends on solar radiation and wind speed. Using regression analysis the coefficients in (10) were obtained. The obtained indoor temperature predicting model is

$$
\begin{aligned}
T_{\text {in }}= & 0.81820 T_{\text {out }}+0.013562(\mathrm{RH})_{\text {out }}-0.12907 V_{w} \\
& +0.00038 I+8.18
\end{aligned}
$$

with $R^{2}=0.950$ and standard error of \pm 5 .

Figure 10 shows the comparison of the measured indoor temperature (February to July) and the predicted indoor temperature using the prediction model (11). The predicted indoor temperature using the developed model is in good agreement (95\%) with the measured temperature values.

From (11) it can be noted that the outdoor temperature, solar radiation, and outdoor relative humidity have a positive contribution to the indoor temperature; that is, when the outdoor temperature, solar radiation, and relative humidity increase the indoor temperature also increases. But when the wind speed increases the tendency is to lower the indoor temperature, that is, negative contribution. From the models it was seen that the outdoor weather parameters do have varying impact on the indoor temperature but with highest sensitivity to the outdoor temperature variation. The determination of the sensitivity of the models revealed that 


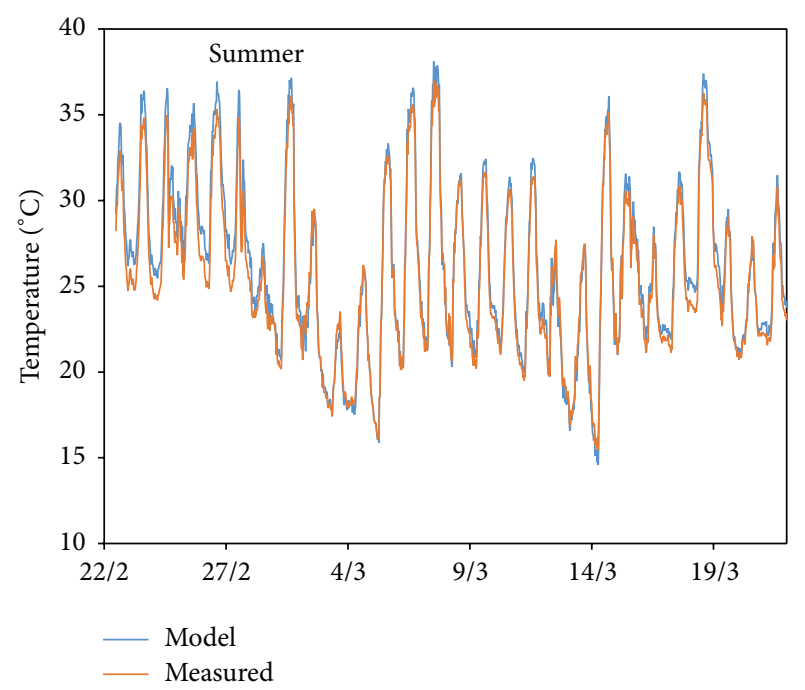

FIGURE 11: Summer comparison of the measured and the modeled temperatures.

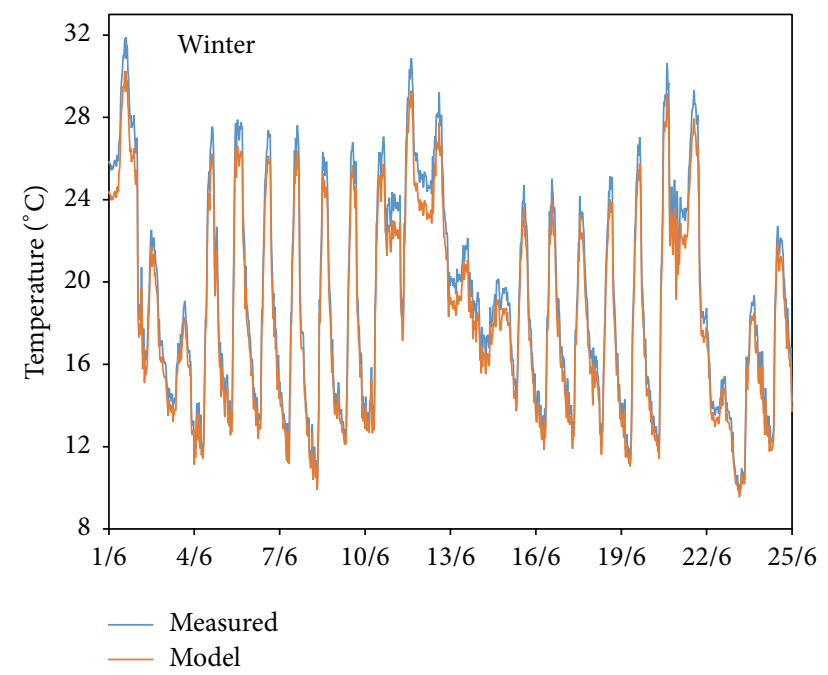

FIGURE 12: Winter comparison of the measured and the modeled temperatures.

the indoor temperature is $89 \%$ dependent on the outdoor temperature, $2 \%$ on relative humidity, $3.5 \%$ on wind speed and direction, $4.6 \%$ on solar radiation, and $0.9 \%$ on other undefined parameters. From Figure 10 it can be seen that the predicted temperatures agree well with the measured data; however, at high temperatures there are significant differences with the measured temperature being higher than the predicted. The difference between the measured and the predicted temperatures is mostly noticed at peak temperatures. The daily mean peak temperature differences of the measured and the predicted temperatures are more pronounced in summer (5\%) than in winter (4\%). Figures 11 and 12 show the comparison of the measured and modeled indoor temperatures for summer and winter, respectively.

Significant differences were noted during cooking periods when a lot of heat was generated indoors, resulting in

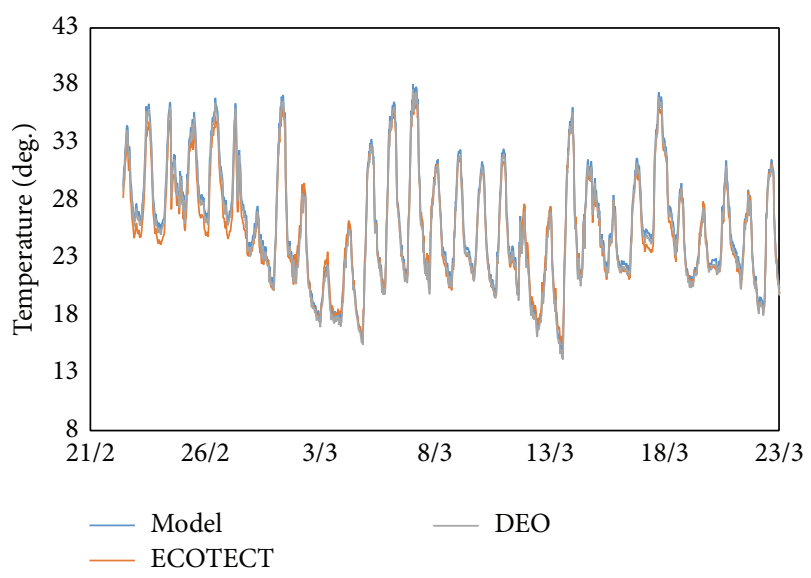

FIGURE 13: Comparison of simulation results of ECOTECT, DOE, and the model.

much higher measured indoor temperature than the model can predict. However, measured and predicted minimum temperatures were found to be in good agreement with small differences of about $0.5 \%$ for summer and $0.6 \%$ for winter. The model was found to predict lower than the minimum measured temperatures. It is worth mentioning that the activities of the occupancies play an important role in indoor temperature distribution. The results suggest that the new developed model equation can be used to predict the indoor temperature for a high thermal building (houses constructed from fly ash bricks) with a passive solar design in the South African type of climate.

3.6. The Comparison of the Model with ECOTECT and DOE Simulation Results. Figure 13 shows a comparison of the simulation results using ECOTECT and DOE and the developed predictive model. It was observed that the simulation results agree very well with the developed model. At minimum temperatures ECOTECT was observed to record the lowest values followed by DOE, but at peak temperatures the three were observed to agree very well. This means the model can be used to predict the instantaneous indoor temperature if the instantaneous outdoor weather parameters are known thus allowing architects to predict the indoor temperature.

\section{Conclusions}

Indoor temperatures within buildings are dynamic as there are a number of stochastic activities which take place indoors. The indoor temperature prediction formula was modeled. It was found that the instantaneous indoor temperature could be predicted if the outdoor weather variables are known for a given house design constructed using specific building materials. Outdoor temperature was found to be the most influential parameter on the indoor temperature distribution. Relative humidity, temperature, and solar radiation were found to have an incremental effect on the indoor temperature; that is, when these parameters increase the tendency is to increase the indoor temperature. Wind speed was found to have lowering effect on the indoor temperature; that is, when 
the wind speed increases the effect is to decrease the indoor temperature. The model was found to be in good agreement with simulations results using ECOTECT building design computer software and DOE building computer simulation software. Results also suggest that the developed model can be used to predict the instantaneous indoor temperature distribution for a specific house design resulting in thermally comfortable indoor environment with minimal energy consumption.

\section{Conflict of Interests}

The author declares that there is no conflict of interests regarding the publication of this paper.

\section{References}

[1] T. Olofsson, J.-U. Sjögren, and S. Andersson, "Energy performance of buildings evaluated with multivariate analysis," in Proceedings of the Building Simulation Conference, pp. 891-898, Montreal, Canada, 2005.

[2] C. Federspiel, Q. Zhang, and E. Arens, "Model-based benchmarking with application to laboratory buildings," Energy and Buildings, vol. 34, no. 3, pp. 203-214, 2002.

[3] H. Li, B. Lin, X. Zhou, Y. Zhu, G. Han, and F. Meng, "The design of a comfortable thermal environment by simulation: a case study," in Proceedings of the Building Simulation Conference, pp. 1820-1825, Beijing, China, September 2007.

[4] G. Makaka and E. Meyer, "Temperature stability of traditional and low-cost modern housing in the Eastern Cape, South Africa," Journal of Building Physics, vol. 30, no. 1, pp. 71-86, 2006.

[5] W. Abanomi and P. Jones, "Passive cooling and energy conservation design strategies of school buildings in hot, arid region, Riyadh, Saudi Arabia," in Proceedings of the International Conference "Passive and Low Energy Cooling for the Built Environment", Santorini, Greece, 2005.

[6] T. A. Reddy and D. E. Claridge, "Using synthetic data to evaluate multiple regression and principal component analyses for statistical modeling of daily building energy consumption," Energy and Buildings, vol. 21, no. 1, pp. 35-44, 1994.

[7] B. W. Olesen and G. S. Brager, "A better way to predict comfort: The New ASHRAE standard 55-2004," August 2004, http://escholarship.org/uc/item/2m34683k.

[8] B. Givoni and F. Vecchia, "Predicting thermal performance of occupied houses," in Proceedings of the 18th International Conference on Passive and Low Energy Architecture (PLEA '01), pp. 701-706, Florianoplis, Brazil, 2001.

[9] ISO, "Thermal environments-specifics relating to appliance and methods for measuring physical characteristics of the environment," ISO Standard 7726, International Standards Organization, Geneva, Switzerland, 1985.

[10] B. Givoni, Climate Considerations in Building and Urban Design, Van Nostrand Reinhold, New York, NY, USA, 1998.

[11] D. M. Ogoli, "Predicting indoor temperatures in closed buildings with high thermal mass," Energy and Buildings, vol. 35, no. 9, pp. 851-862, 2003.

[12] B. Givoni, "Effectiveness of mass and night ventilation in lowering the indoor daytime temperatures. Part I: 1993 experimental periods," Energy and Buildings, vol. 28, no. 1, pp. 25-32, 1998.
[13] E. L. Kruger and E. M. Dumke, "Thermal performance evaluation of the technological village in Curitiba-Brazil," in Proceedings of the 18th International Conference on Passive and Low Energy Architecture (PLEA '01), pp. 707-711, Florianopolis, Brazil, 2001.

[14] H. M. Künzel, A. Holm, D. Zirkelbach, and A. N. Karagiozis, "Simulation of indoor temperature and humidity conditions including hygrothermal interactions with the building envelope," Solar Energy, vol. 78, no. 4, pp. 554-561, 2005.

[15] C. Inard, H. Bouia, and P. Dalicieux, "Prediction of air temperature distribution in buildings with a zonal model," Energy and Buildings, vol. 24, no. 2, pp. 125-132, 1996.

[16] P. Hemmi, Room temperature distribution [Ph.D. dissertation], ETH Zürich, Zürich, Switzerland, 1967.

[17] X. Peng and A. H. C. van Paassen, "A type of calculation of indoor dynamic temperature distributions," in Proceedings of the 4th International Conference on System Simulation in Buildings (SSB '94), pp. 57-68, Liege, Belgium, 1994.

[18] Q. Chen, X. Peng, and A. H. C. van Paassen, "Prediction of room thermal response by CFD technique with conjugate heat transfer and radiation models," Ashrae Transactions, vol. 101, part 2, 11 pages, 1995.

[19] South Africa Weather Service, 2006, http://www.weathersa.co .za/.

[20] B. Givoni, Climate and Architecture, Applied Science Published, London, UK, 1976. 


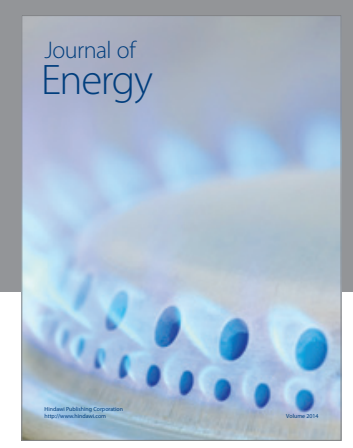

Journal of

Industrial Engineering
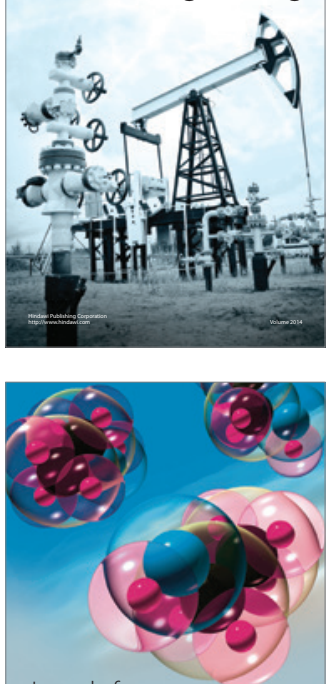

Fuels
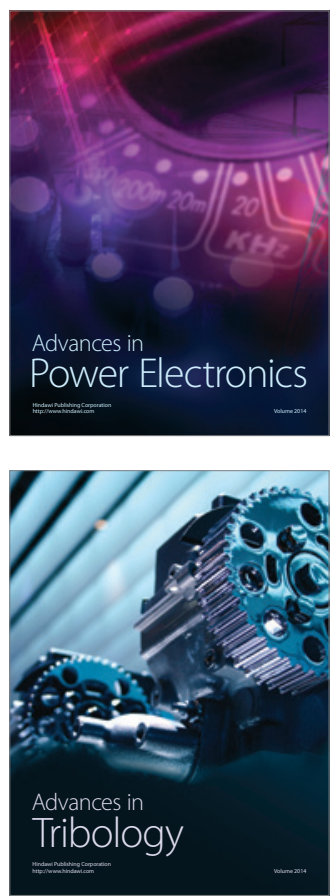

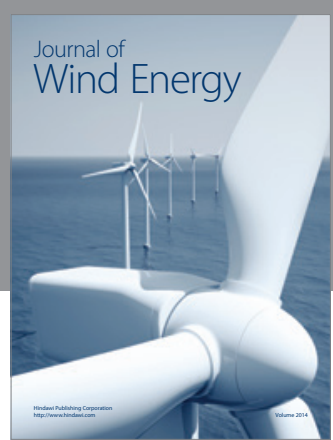

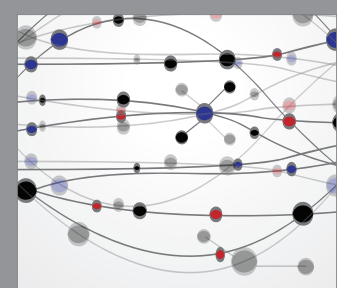

The Scientific World Journal

Submit your manuscripts at http://www.hindawi.com

Journal of

Structures
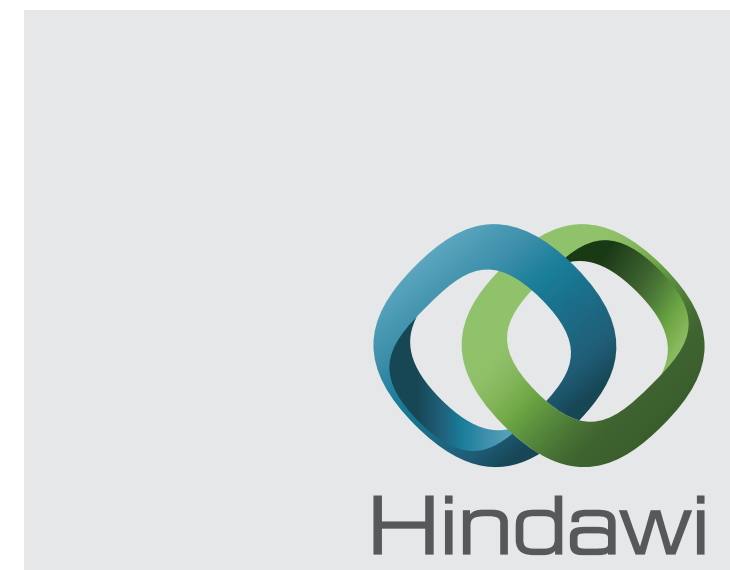

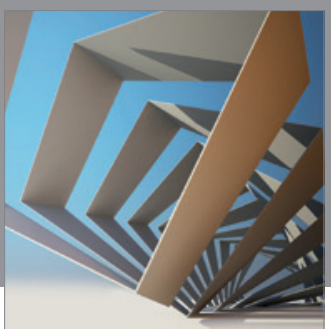

Rotating

Machinery
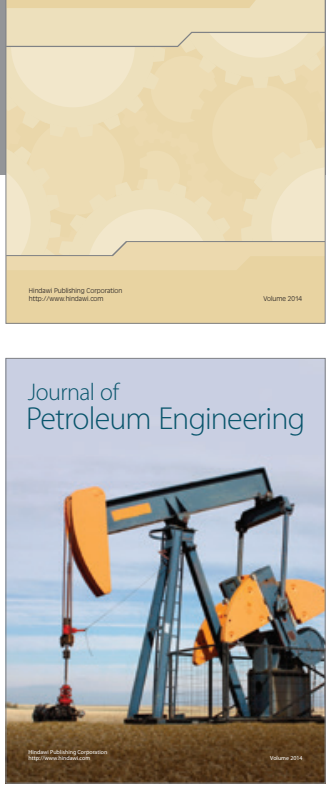

Journal of

Solar Energy
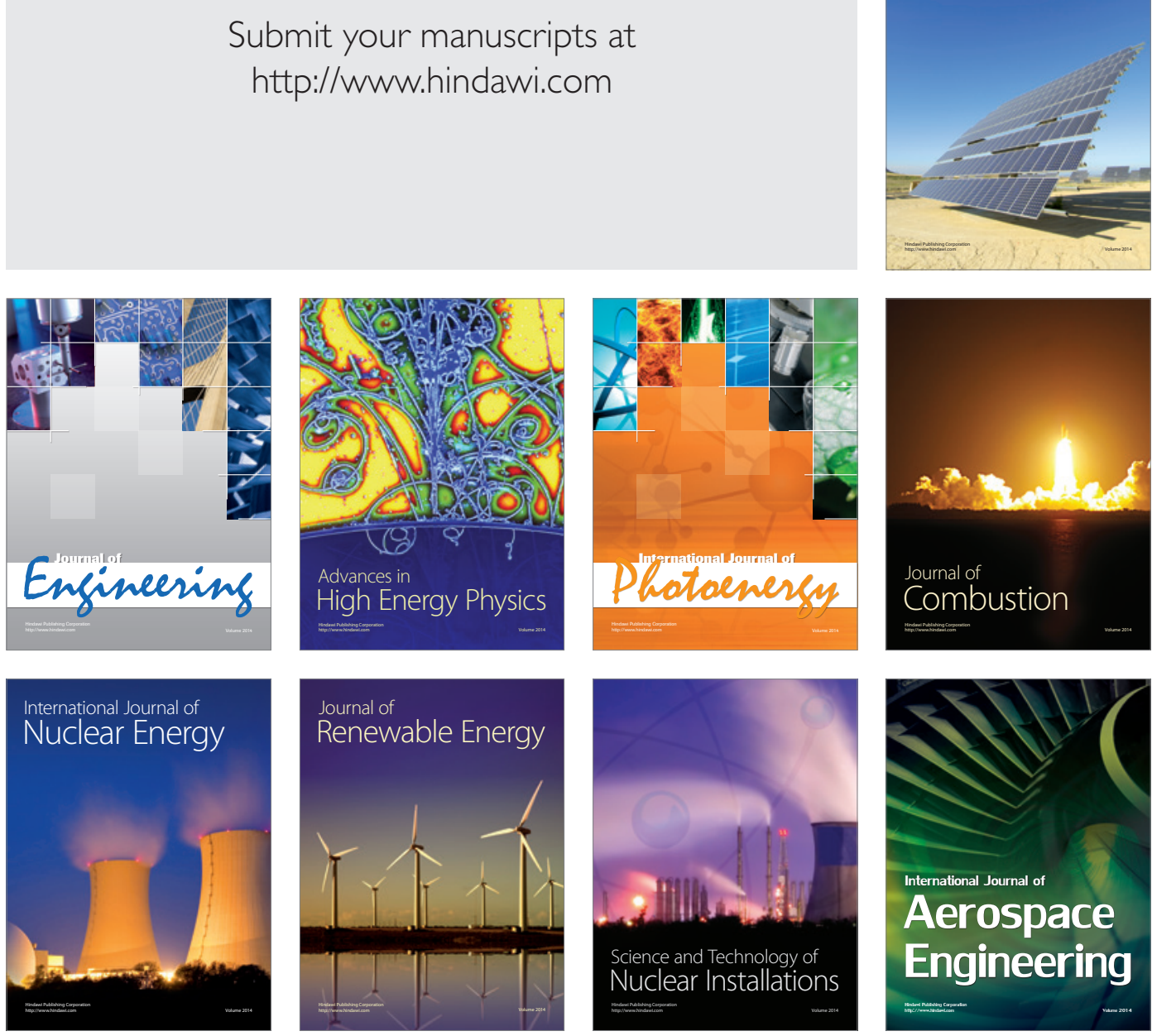